\title{
Fabrication and characterization of microlenses made of tellurite and heavy metal oxide glass developed with hot embossing technology
}

\author{
R. Kasztelanic · I. Kujawa • R. Stępień · J. Cimek · K. Haraśny • \\ M. Klimczak • A. J. Waddie - M. R. Taghizadeh • R. Buczyński
}

Received: 29 April 2013 / Accepted: 12 October 2013 / Published online: 25 October 2013

(C) The Author(s) 2013. This article is published with open access at Springerlink.com

\begin{abstract}
In this paper we describe the work on application of hot embossing process to fabrication of micro-optical elements transmitting in the visible, near infrared and mid-infrared part of spectrum, using multi-component soft glasses as starting materials. Description of used hot embossing (HE) process is provided, followed by discussion of rheological and viscosity properties of several glass types considered for demonstrator fabrication experiment. Demonstrator microlenses were fabricated from lead-bismuth-gallium oxide (PBG08) and tellurite glasses (TWPN/I/6), with transmission windows extending from the visible up to the mid-infrared (up to around $6.5 \mu \mathrm{m}$ ). Fabricated elements, which included diffractive and refractive lenses and lens arrays, were examined in context of homogeneity (quality of pattern replication) and obtained optical properties ( $\mathrm{M}^{2}$, focal length, resolution). A demonstrator microscope objective was constructed using refractive plano-concave, plano-convex and biconvex lenses fabricated with the HE setup and its optical characteristics were provided.
\end{abstract}

Keywords Hot embossing $\cdot$ Mid-infrared microlens $\cdot$ Micro-optics fabrication

\section{Introduction}

Applications of micro-optical elements in the mid-infrared received significant attention in the recent years (Waynant et al. 2001). Such micro-optical elements are used, among others, in modern IR vision systems and guiding systems, which require focusing of mid-infrared

R. Kasztelanic · R. Buczyński $(\bowtie)$

Faculty of Physics, University of Warsaw, ul. Pasteura 7, 02-093 Warsaw, Poland

e-mail: rbuczyns@igf.fuw.edu.pl

I. Kujawa · R. Stępień · J. Cimek · K. Haraśny · M. Klimczak · R. Buczyński

Institute of Electronic Materials Technology, ul. Wólczyńska 133,

01-919 Warsaw, Poland

A. J. Waddie · M. R. Taghizadeh

Institute of Photonics and Quantum Sciences, School of Engineering and Physical Sciences,

Heriot-Watt University, Edinburgh EH14 4AS, Scotland, UK 
radiation into small areas without introducing attenuation. Vast applicability of diffractive and refractive optical micro-components compatible with this spectral area, calls for optimizing their production i.e. using new classes of materials and more effective methods of low-cost, mass fabrication (Kujawa et al. 2012).

Various techniques are used to manufacture micro-optical elements operating in the midinfrared, with each having different advantages. Among the most versatile are lithography, epitaxy, ion techniques and micromechanical processing (Schubert et al. 2006). In this lineup, hot embossing (HE) stands out with its cost effective mass-producing capability and relatively good surface parameters (Yasui et al. 2007; Takahashi et al. 2005, 2007). Unfortunately, this technology is mostly applied to processing of polymers in the fabrication of microoptical elements (Heckele and Schomburg 2004; Chen and Jen 2004). However, compared to polymers, glasses possess superior thermal stability and optical transmission properties. To process glass, high temperatures are required, due to the viscosity changes (for soft glassesabove $400{ }^{\circ} \mathrm{C}$ ). After reaching the specified temperature, glass can be mechanically shaped to reproduce the desired pattern in a glass substrate. On the other hand, hot embossing of glass elements is more difficult than in the case of polymer elements, because glass is formed at higher temperatures. It is also critical to avoid crystallization, which may occur during heating, embossing or cooling of the glass element, and which renders the element optically useless. Therefore, it is crucial to choose the right composition of glass. Among the criteria for selection of glass for a particular HE fabrication process, are the rheological properties of the chosen glasses in the applied temperature range, which have to be considered carefully. Another issue is the choice of the material for the mould, as its thermal expansion coefficient must be close to that of the glass, and the glass must not permanently adhere to the mould during any of the processing steps.

So far, only a few groups have reported using the HE process for fabrication of glass micro-optical elements by different methods. They all have certain drawbacks. In the case of pattern processing in coated silica glass (Edelmann et al. 2012) it is necessary to additionally coat the glass substrate with thin metal, carbon and oxide layers to reduce the sticking of glass melts to the moulding tools. In the case of metallic glasses (Pan et al. 2008; Chu et al. 2007) the process of the glass manufacturing is complicated. This situation motivates us to find new kinds of glass and to optimize the HE process, in order to effectively fabricate micro-optical elements including refractive and diffractive lenses to be applied in the infrared part of spectrum.

\section{Hot embossing, glass and material for stamp selection}

The HE process used for the manufacturing of glass micro-optical elements is schematically shown in Fig. 1a. The technological process of HE can be divided into three main phases (Fig. 1b). In the first, initial phase, the material and the stamps are heated to the desired temperature. The working area of the device is often surrounded by vacuum, which improves the stamped pattern image in the material and protects the stamp. Another way to protect the surface of the stamp from oxidation is to carry out the process in an inert gas atmosphere. The second phase of the embossing process, i.e. pressing, takes place after the optimal temperature of the material has been reached. At this stage, the material is subject to pressure from the stamp, which transfers the pattern image. The parameters which are significant for the process include: an accurately stabilized temperature, the pressure force and dynamics, time of stopping the stamp and the rate of its retraction from the surface. The material chosen for the stamp, the size of the heating chamber, the vacuum level, type of inert gas and moment 


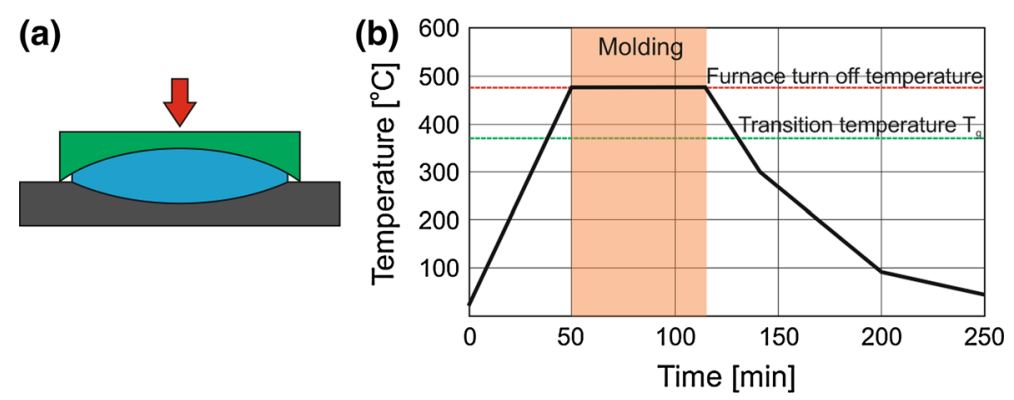

Fig. 1 Scheme of the hot embossing process (a) and the duty cycle of the HE process (b) for mini lens development

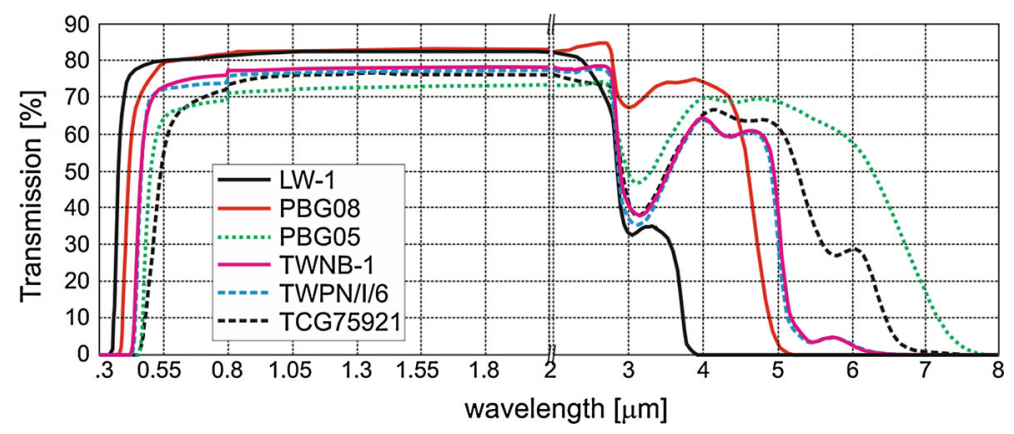

Fig. 2 Spectral transmission of the glasses for a $2 \mathrm{~mm}$ sample

Table 1 Oxide composition of the tested glasses

\begin{tabular}{|c|c|c|c|c|c|c|c|c|c|c|c|c|c|}
\hline \multirow[t]{2}{*}{ Glass symbol } & \multicolumn{13}{|c|}{ Oxide content (wt $\%$ ) } \\
\hline & $\mathrm{SiO}_{2}$ & $\mathrm{PbO}$ & $\mathrm{Bi}_{2} \mathrm{O}_{3}$ & $\mathrm{Ga}_{2} \mathrm{O}_{3}$ & $\mathrm{CdO}$ & $\mathrm{B}_{2} \mathrm{O}_{3}$ & $\mathrm{ZnO}$ & $\mathrm{Tl}_{2} \mathrm{O}$ & $\mathrm{GeO}_{2}$ & $\mathrm{WO}_{3}$ & $\mathrm{Na}_{2} \mathrm{O}$ & $\mathrm{TeO}_{2}$ & $\mathrm{Nb}_{2} \mathrm{O}_{5}$ \\
\hline LW1 & 5.2 & 63.7 & - & - & - & 14.6 & 16.5 & - & - & - & - & - & - \\
\hline PBG08 & 14.1 & 39.2 & 27.3 & 14.3 & 5.3 & - & - & - & - & - & - & - & - \\
\hline PBG05 & - & 40,6 & 42.4 & 17.0 & - & - & - & - & - & - & - & - & - \\
\hline TWNB1 & - & - & - & - & - & - & - & - & - & 28.6 & 1.8 & 67.2 & 2.4 \\
\hline TWPN/I/6 & - & - & - & - & - & - & - & - & - & 34.8 & 1.8 & 60.3 & 3.1 \\
\hline TCG75921 & - & 28.6 & 31.3 & 12.6 & 4.9 & - & - & 13.4 & 9.2 & - & - & - & - \\
\hline
\end{tabular}

of the process chamber area unsealing, also affect the HE process (Worgull 2009). During the third phase, the element can be cooled and removed from the stamping device. Care has to be taken, that the fabricated element does not suffer mechanical damage or crystallization at this final phase.

As noted above, important factors that affect the quality of the received elements are glass, its resistance to crystallization and the material of stamp. For the initial experiments in this work, we selected glasses known for their appreciable transmission characteristics in the visible and mid-infrared parts of spectrum (Fig. 2) (Stepien et al. 2011; Lorenc et al. 2008). The composition of the selected glasses is shown in Table 1. Next, the glasses were examined for their thermal properties (Table 2). 
Table 2 Parameters of the glasses considered for the experiment

\begin{tabular}{|c|c|c|c|c|c|c|}
\hline \multirow[t]{2}{*}{ Parameter } & \multicolumn{6}{|c|}{ Glass symbol } \\
\hline & LW-1 & PBG08 & PBG05 & TWNB-1 & TWPN/I/6 & TCG75921 \\
\hline $\mathrm{n}_{\mathrm{d}}$ & 1.846 & 1.938 & 2.350 & 2.155 & 2.149 & 2.170 \\
\hline$\alpha\left(10^{-6} \mathrm{~K}^{-1}\right)$ & 8.31 & 8.30 & 11.05 & 15.51 & 14.40 & 10.78 \\
\hline $\operatorname{DTM}\left[{ }^{\circ} \mathrm{C}\right]$ & 420.0 & 500.0 & 468.5 & 368.0 & 385.0 & 392.2 \\
\hline \multicolumn{7}{|l|}{ Temp. $\left[{ }^{\circ} \mathrm{C}\right]$} \\
\hline $\mathrm{T}_{\mathrm{g}} \log \eta=13.4$ & 400.0 & 463.2 & 443.0 & 355.9 & 365.0 & 368.5 \\
\hline $\mathrm{T}_{\mathrm{Z}} \log \eta=9.0$ & 421.0 & 542.0 & 490.0 & 370.0 & 395.0 & 395.0 \\
\hline $\mathrm{T}_{\mathrm{k}} \log \eta=6.0$ & 450.0 & 615.0 & 540.0 & 395.0 & 415.0 & 445.0 \\
\hline $\mathrm{T}_{\mathrm{pk}} \log \eta=4.0$ & 487.5 & 690.8 & 575.0 & 440.0 & 460.0 & 485.0 \\
\hline $\mathrm{T}_{\mathrm{r}} \log \eta=2.0$ & 645.0 & 800.5 & 680.0 & 510.0 & 535.5 & 560.0 \\
\hline $\mathrm{d}\left[\mathrm{g} / \mathrm{cm}^{3}\right]$ & 5.625 & 5.798 & 8.020 & 5.795 & 5.881 & 7.410 \\
\hline \multicolumn{7}{|l|}{ Transmission [nm] } \\
\hline Lower limit & 380 & 380 & 460 & 425 & 420 & 460 \\
\hline Upper limit & 3700 & 5200 & 8000 & 6700 & 6850 & 7400 \\
\hline $\mathrm{A}[\mathrm{dB} / \mathrm{m}]$ & no data & $5-2200$ & no data & no data & no data & $16-2100$ \\
\hline
\end{tabular}

We established that glasses PBG08 and TWPN/I/6 are characterized by the best resistance to crystallization (Kasztelanic et al. 2013; Kujawa et al. 2013).

Another significant technological issue is the adhesion of the glasses to the mould surface during thermal treatment. What is essential for this process is not only the viscosity, but also the surface tension and the wetting between the glass and the material of the mould (stamp) during embossing. We studied the interaction between all the presented glasses and the mould material, as well as its dependence on temperature, in order to estimate their adhesion. Glass adhesion was tested for various metals (steel, aluminum, cast, copper, bronze, titanium and brass) and for nonmetallic materials (quartz monocrystal, silicon monocrystal, fused silica glass and graphite). Considering only the criterion of glass adhesion to the stamp material, it can be concluded that for each glass tested it is possible to choose the material of the moulding tools and the temperature, for which the two parts could be separated after the HE process. However, the temperature range enabling the separation of the elements does not always coincide with the optimum temperature of the embossing process, which leads to crystallization of the glass and the damage of the fabricated components. Moreover, not all of the materials considered were easy to process and form micro-patterns necessary to fabricate e.g. Fresnel lenses. Finally, for further testing, we selected three materials for the pattern stamps: brass 58 and steel 1H18N9T for metal stamps and fused silica glass for the nonmetallic stamp.

\section{Lens fabrication}

Taking into account the parameters of glass adhesion to moulds made of different materials and the ability to manufacture appropriate forms, further work was carried out with the use 

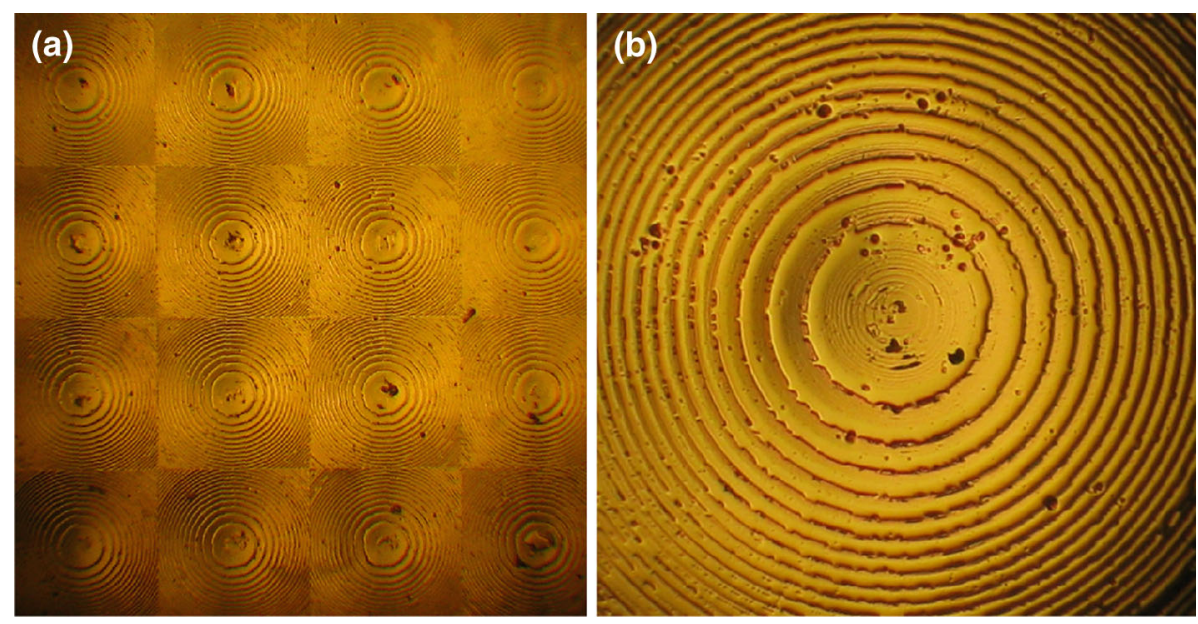

Fig. 3 Image of the array of the Fresnel lenses obtained from the optical microscope. Magnification $\times 3.2(\mathbf{a})$ and $\times 10(\mathbf{b})$

of moulds made of fused silica glass. In the case of diffractive elements for the mid-infrared, the required thickness of the fabricated structure is within several micrometers, which is a significant technological challenge. That is why the moulds were fabricated from quartz glass with the use of ion etching technology. A single mould consisted of an array of $64(8 \times 8)$ of Fresnel lenses, each with a diameter of $750 \mu \mathrm{m}$ (Figs. 3, 4a).

The lenses were pressed out of round, $2 \mathrm{~mm}$ thick glass samples, made of the PBG08 glass, which were $2 \mathrm{~cm}$ in diameter. The quality of the replication of small elements in the Fresnel lens depends on the time, the pressure and the temperature of the replication process. The forming range for glasses is limited to the viscosity of $10^{13}-10^{9} \mathrm{~Pa}$. The imperfections in the replication visible in Figure 3, result from local pollution of the stamp with dust particles. These distortions were transferred into replica during embossing process. During the process of unmoulding, such distortions may cause local microstress, leading to the emergence of flaws on the surface.

In order to investigate the influence of the parameters of the hot embossing process on the quality of the obtained structures, we carried out several trials of element replication for different temperatures, pressing times and pressures (Kasztelanic et al. 2013; Kujawa et al. 2013). As for the separation of the sample from the mould, the optimal parameters established were: pressure of 32.5 bar and temperature of the moulding $\mathrm{T}_{\mathrm{s}}=518^{\circ} \mathrm{C}$. The examplary results of the replication for the two different periods of embossing time are presented in Fig. 4b, c.

The cross-sections presented above made with the use of a white light interferometer (Veeco Wyko NT2000) prove, that increasing the time of the process allows for better precision and for creating elements of deeper structure. However, increasing the time of the HE process above $2 \mathrm{~h}$, leads to adhesion of the sample to the mould with no possibility to separate the two.

In the case of refractive lenses, we have tested the development of different shapes of lenses: plano-concave, plano-convex and biconvex lenses. A series of test processes were carried out to optimize its parameters. In particular, the working temperature, imprint force, heating and cooling rates were optimized. The optimum embossing temperature was established at $544^{\circ} \mathrm{C}$ for PBG08 and $446^{\circ} \mathrm{C}$ for TWPN/I/6 glass. The constant imprint force of 32 bar was used in both cases. 
(a)
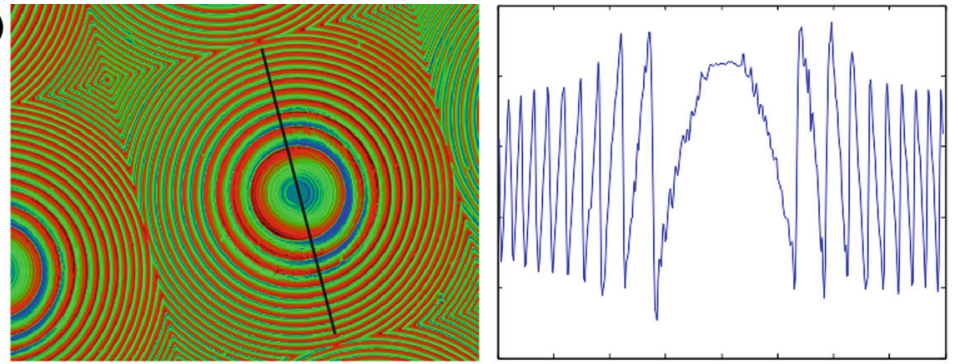

(b)
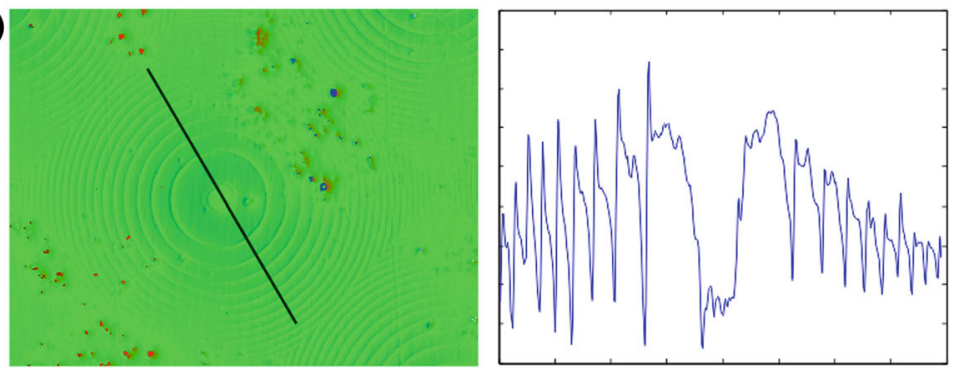

(c)
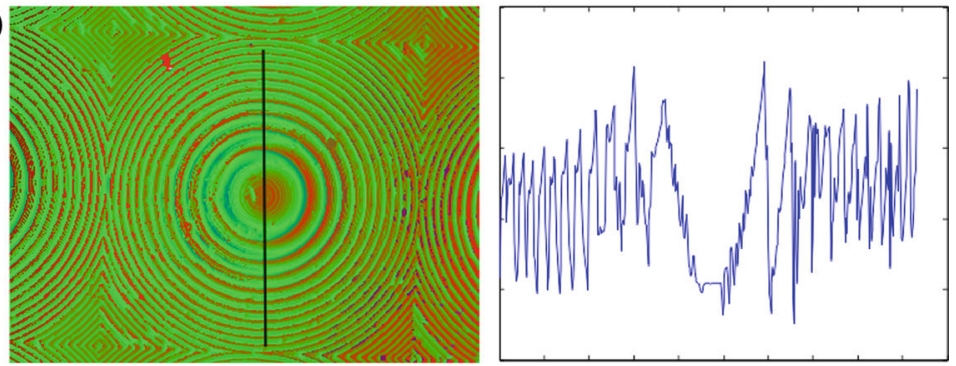

Fig. 4 Mould (a) and replicas made in the temperature of $518^{\circ} \mathrm{C}$, pressure of $32.5 \mathrm{bar}$ for the different timing of the process: $40 \mathrm{~min}(\mathbf{b}), 120 \mathrm{~min}(\mathbf{c})$

The profilometer measurements were used to study the surface curvature and the quality of the optical surface of moulded lenses (Fig. 5). Only a central areas of the moulded lenses were measured due to white light interferometer limits. The results obtained for various stamps show identical curvature of the mould and the replicated lenses. The quality of the obtained surface is worse than the mould. Some cracks occurring on the surface result from a mismatch of the expansion coefficients of the moulded soft glass and fused silica of the mould (Fig. 5b, c). Furthermore, the wrong choice of the temperature or length of processing cycle results in formation of air bubbles or crystallization of glass (Fig. 6).

\section{Optical properties of fabricated lenses}

We carried out several optical measurements for the fabricated Fresnel lenses. They consisted in checking the quality of focusing within the visible light spectrum to mid-infrared. An example of the results obtained for light wavelength of $\lambda=1,300 \mathrm{~nm}$ is presented in Fig. 7. The following images present the intensity of the light wave in the various planes around the focal plane of the Fresnel lenses, which in this case is $10 \mathrm{~mm}$. Importantly, we obtained high 
(a)
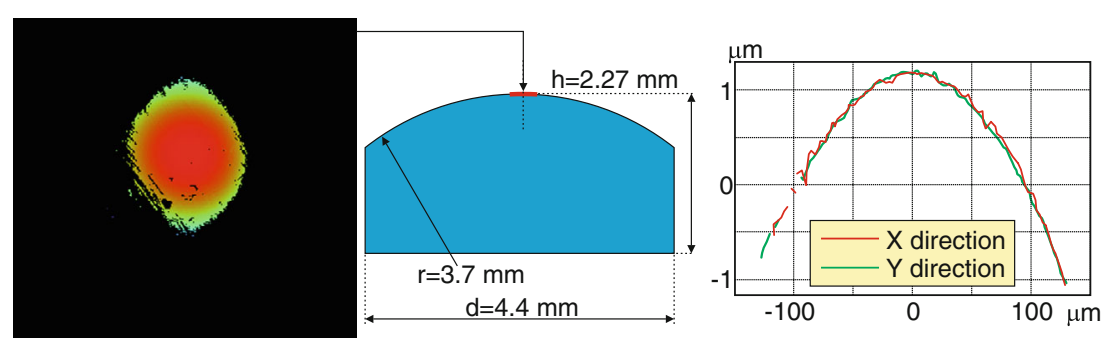

(b)
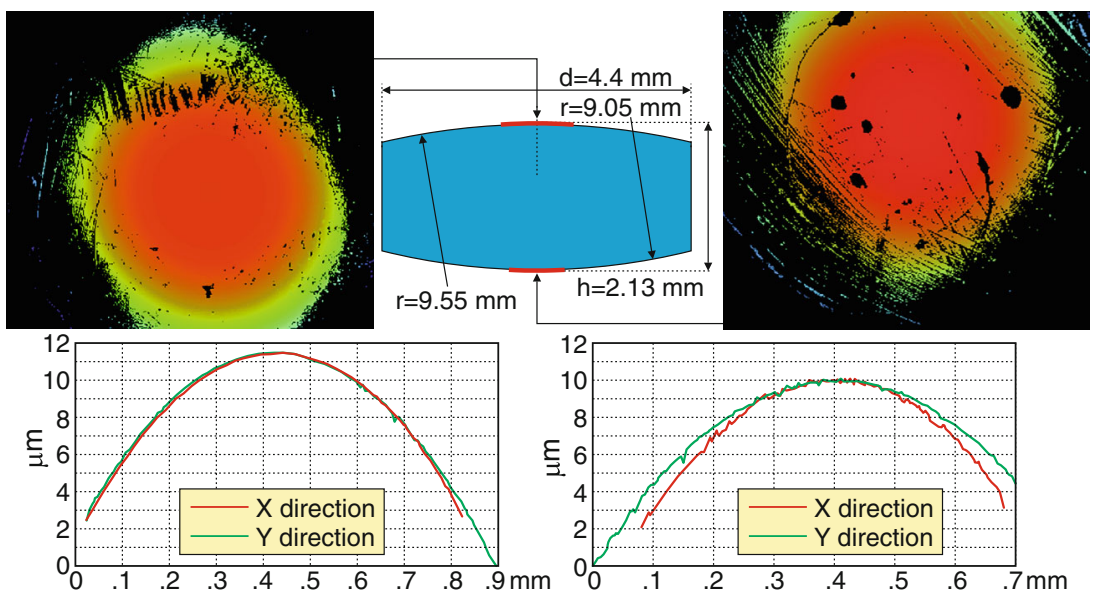

(c)
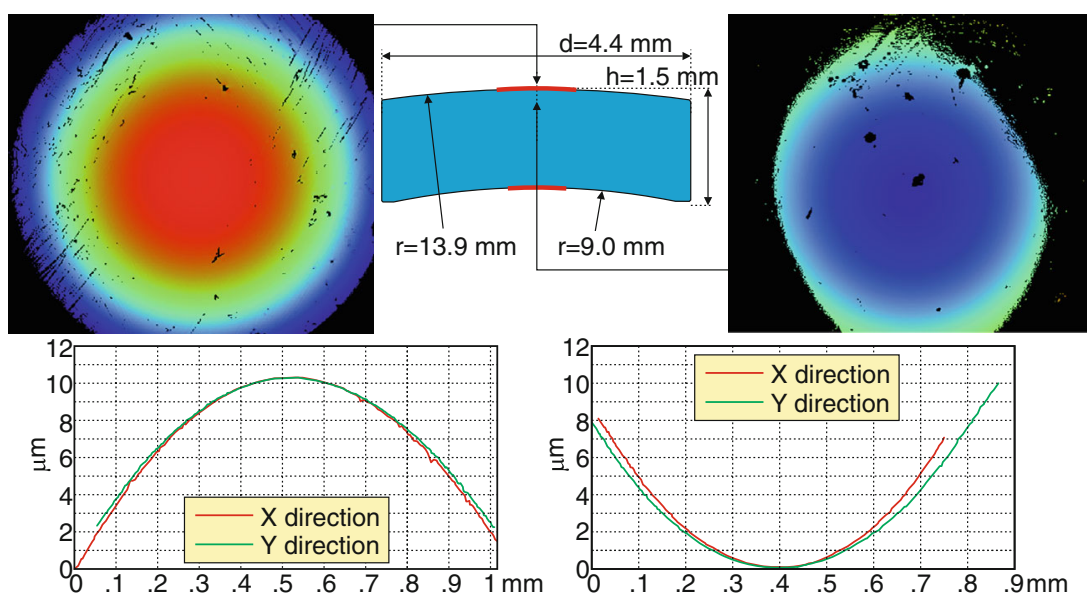

Fig. 5 Scan of surface of the various lenses made of TWPN/I/6 glass: (a) plano-convex, (b) biconvex and (c) concave-convex (red lines on the lens surface represents parts of region where the results from profilometer was obtained)

homogeneity of light intensity in the particular foci, independent of their location. The largest experimentally measured difference does not exceed $10 \%$. For each of Fresnel lenses, we also performed measurements of the $\mathrm{M}^{2}$ parameter $\left(\mathrm{M}^{2}\right)$ according to the diagram shown in 


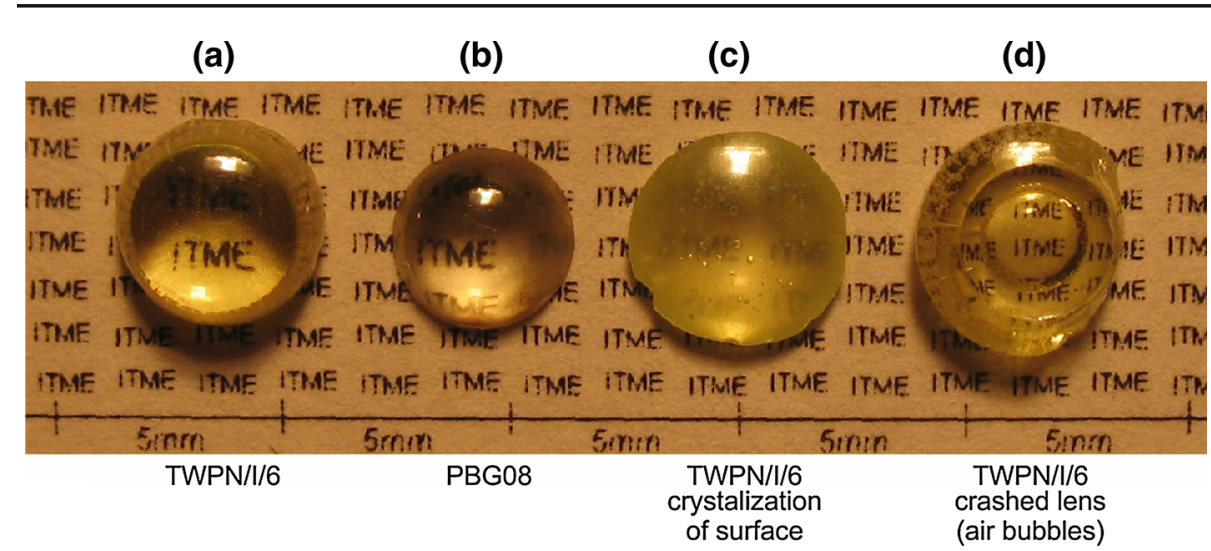

Fig. 6 Imaging properties of the developed biconvex mini lenses made of TWPN/I/6 and PBG08 glasses
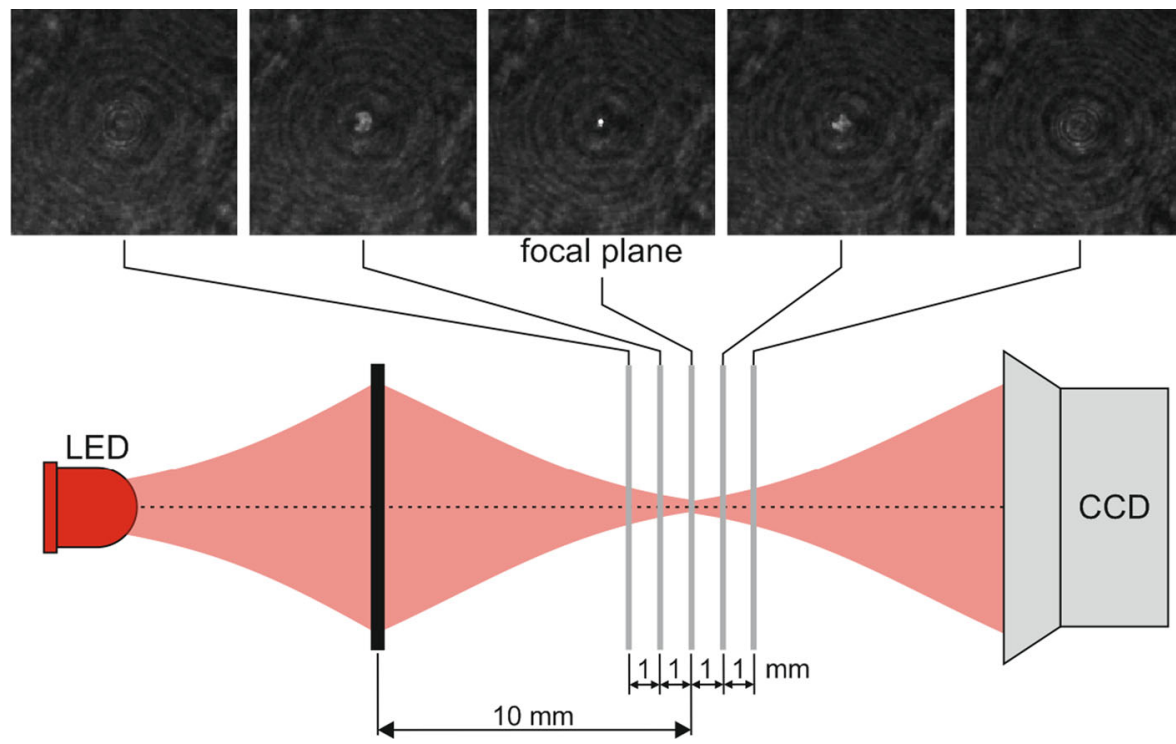

Fig. 7 Focusing light through the Fresnel lenses array. Light intensity at several planes for one Fresnel lens

Fig. 8. It allows to determine the quality of the lenses based on Gaussian beam transformation. The results also showed high homogeneity of the fabricated lenses.

For refractive lenses optical and imaging properties were verified with various methods. We measured the focal length of lenses and compared the results with the theoretical values obtained on the basis of the refractive index, thickness and measured surface curvature of the lens (Fig. 5). The obtained results are summarized in Table 3. The measurements were carried out for the wavelength of 1,300 nm. For most of the lenses, the difference between the expected and the measured focal length, was less than $1 \%$. In case of some lenses, we observed a collapse of the surface (Fig. 9), which was related to too high temperature of the moulding process or too short cooling time.

The resolution of the moulded lenses was verified with standard 1951 USAF resolution test charts. The modulation transfer function (MTF) was obtained by the measurement of the contrast for each resolution test. The MTF is defined as (Holst 1998): 


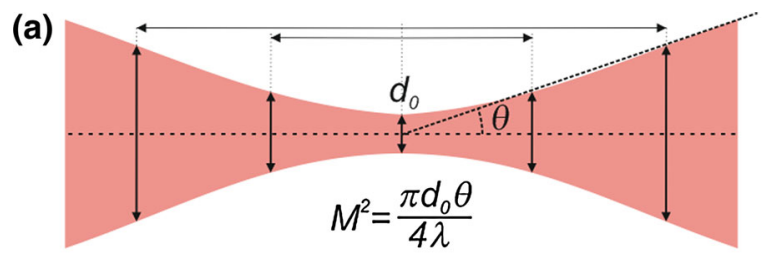

(b)

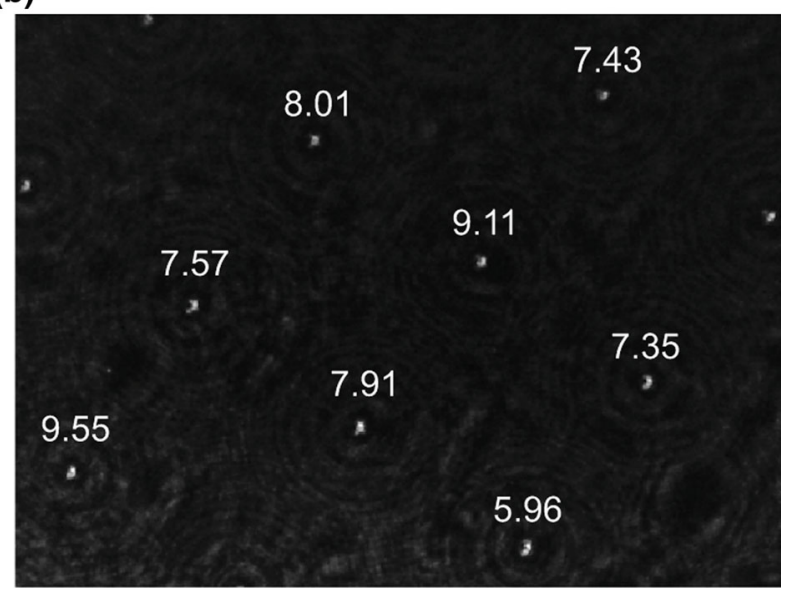

Fig. 8 Scheme (a) and results (b) of measurements of $\mathrm{M}^{2}$ (M-square) for Fresnel lenses array

Table 3 A comparison of calculated and measured focal length for the moulded lenses

\begin{tabular}{llllllll}
\hline Glass & $\begin{array}{l}\text { Diameter } \\
(\mathrm{mm})\end{array}$ & $\begin{array}{l}\text { Thickness } \\
(\mathrm{mm})\end{array}$ & Lens type & \multicolumn{2}{l}{ Curvature $(\mathrm{mm})$} & \multicolumn{2}{l}{ Focal length (mm) } \\
\cline { 5 - 8 } & & & $\mathrm{R} 1$ & $\mathrm{R} 2$ & Measured & Calculated \\
\hline PBG08 & \multirow{2}{*}{3.85} & 1.26 & Plano-convex & Infinity & 2.76 & 3.4 & 3.40 \\
& & 2.81 & Biconvex & 15.01 & 2.62 & 3.0 & 4.35 \\
TWPN/I/6 & 4.4 & 2.06 & Concave-convex & -67.5 & 4.96 & 4.0 & 5.42 \\
& & 1.9 & Plano-convex & Infinity & 5.97 & 7.1 & 7.10 \\
& & 2.13 & Biconvex & 9.55 & 9.05 & 4.4 & 5.25 \\
\hline
\end{tabular}
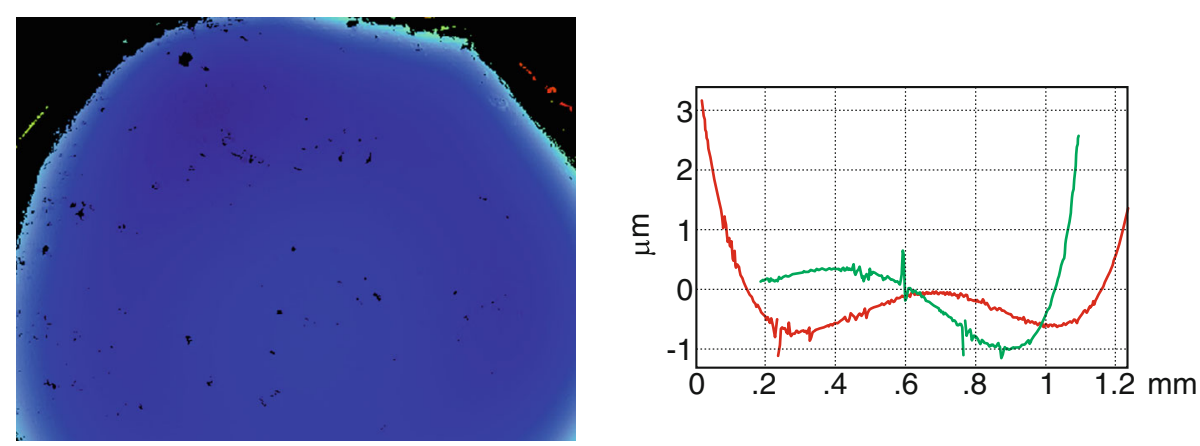

Fig. 9 Surface collapse in the TWPN/I/6 moulded lens with the focal length of $4.4 \mathrm{~mm}$ caused by wrong processing parameters 


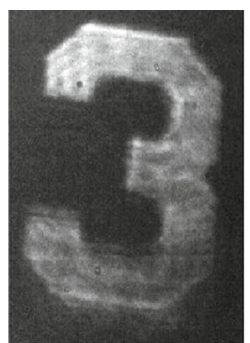

$1.26 \mathrm{Ip} / \mathrm{mm}$

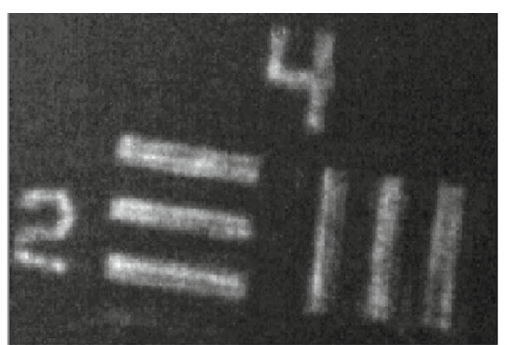

$17.95 \mathrm{Ip} / \mathrm{mm}$

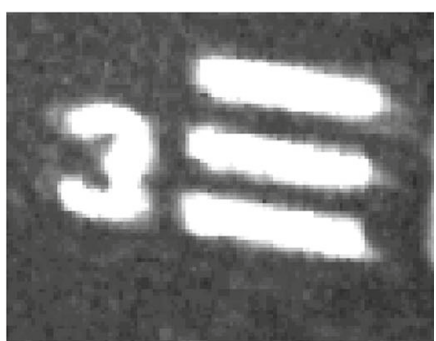

$40.3 \mathrm{Ip} / \mathrm{mm}$

Fig. 10 Imaging of the test targets resolution with various resolution for refractive mini lens made of TWPN/I/6 glass. Measurements are carried out at the wavelength $1300 \mathrm{~nm}$. Resolution units are line pairs per millimeter

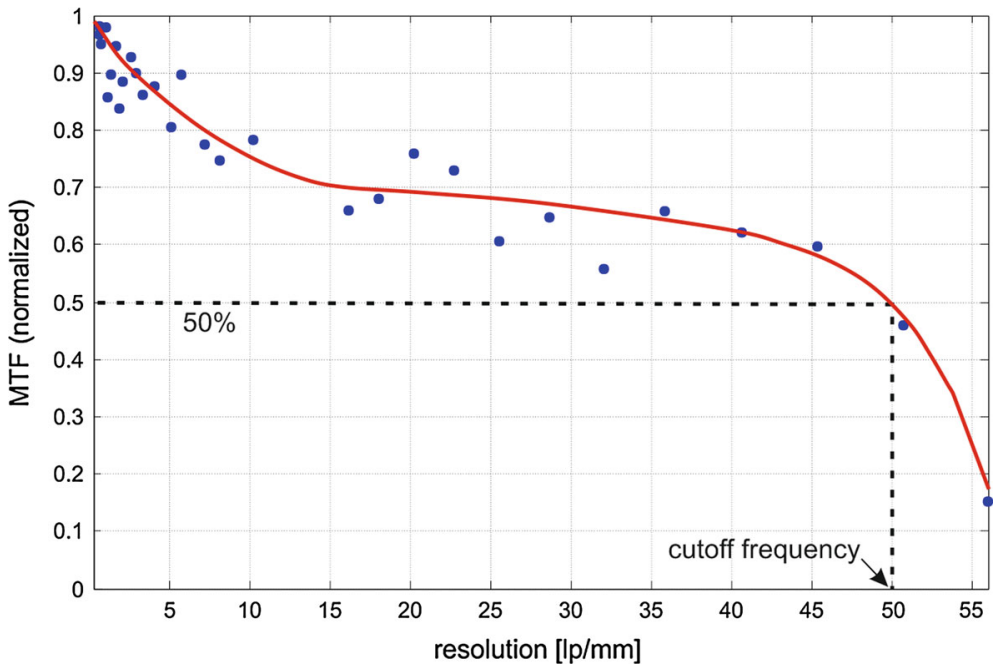

Fig. 11 Measured modulation transfer function for refractive mini lens made of TWPN/I/6 glass with the focal length of $4.15 \mathrm{~mm}$. Cutoff frequency is marked

$$
C=\frac{V_{\min }-V_{\max }}{V_{\min }+V_{\max }}
$$

where $V_{\min }$ and $V_{\max }$ denotes the minimum intensity (pixel value) and maximum intensity, respectively. For the measurements we used a linear CCD camera with gamma correction $\gamma=1$ (Fig. 10).

The MTF is commonly used to measure quality of imaging lenses. It represents how accurately the tested lens reproduces details of a imaged object. The MTF diagram was finally used to determine the cutoff frequency for the moulded lens at the wavelength of $1300 \mathrm{~nm}$. The final result for the $50 \%$ MTF is cutoff frequency of $50 \mathrm{lp} / \mathrm{mm}$ (line pairs per millimeter) (Fig. 11).

The fabricated mini lenses made of TWPN/I/6 were also used for the construction of microscope objectives. In the microscope setup the developed microscope objective was combined with a standard ocular lens eyepiece of $10 \times$ magnification. For this reason, the microscope setup was tested only in the near infrared range at $1300 \mathrm{~nm}$. We experimentally 
verified the resolution to be $50 \mathrm{lp} / \mathrm{mm}$ for the $50 \times$ magnification of the microscope. As a result we established, that the obtained magnification of the moulded objective lenses was $5 \times$.

\section{Conclusions}

In the paper we presented all the major steps involved in the fabrication of refractive and diffractive lenses in the hot embossing process, from the characterization of glasses, to the selection of suitable materials for moulding tools. We showed, that in order to obtain the desired quality of lenses it is crucial to properly select the parameters of the HE process, such as temperature and rate of temperature change, the pressure and time duration of process. The optimal results of lens replication were obtained for the process at the temperature of $544^{\circ} \mathrm{C}$ in case of PBG08 glass and $446^{\circ} \mathrm{C}$ for TWPN/I/6 glass, with the use of low imprinting force.

We obtained reasonable image properties of the developed lenses and we proved the ability of the lens to focus light in the visible and in the mid-infrared spectral range. Finally, we showed that the fabricated lenses can be used for imaging, and may be used as a part of larger optical devices, such as a microscope. Summing up, the results of the optical measurements prove that the HE process is a time- and cost-effective method of producing glass diffractive elements for applications in mid-infrared optics.

Acknowledgments This research was carried out with the financial support from the Polish Ministry of Science and Higher Education research Grant N507 431339 and the project operated within the Foundation for Polish Science Team Programme co-financed by the European Regional Development Fund, Operational Program Innovative Economy 2007-2013.

Open Access This article is distributed under the terms of the Creative Commons Attribution License which permits any use, distribution, and reproduction in any medium, provided the original author(s) and the source are credited.

\section{References}

Lung, C.C., Fuhua, J.: Fabrication of polymer splitter by micro hot embossing technique. Tamkang J. Sci. Eng. 7, 5-9 (2004)

Chu, J.P., Wijaya, H., Wu, C.W., Tsai, T.R., Wei, C.S., Nieh, T.G., Wadsworth, J.: Nanoimprint of gratings on a bulk metallic glass. Appl. Phys. Lett. 90, 034101 (2007)

Edelmann, J., Worsch, C., Schubert, A., Rüssel, C.: Micro structuring of inorganic glass by hot embossing of coated glass wafers. Microsyst. Technol. 16, 553-560 (2012)

Heckele, M., Schomburg, W.K.: Review on micro moulding of thermoplastic polymers. J. Micromech. Microeng. 14, R1-R14 (2004)

Holst, G.C.: Testing and Evaluation of Infrared Imaging Systems, 2nd edn. JCD Publishing/SPIE, Florida/Washington (1998)

Kasztelanic, R., Kujawa, I., Stẹpień, R., Haraśny, K., Pysz, D., Buczyński, R.: Fresnel lens fabrication for broadband IR optics using hot embossing process. Infrared Phys. Technol. 60, 1-6 (2013)

Kujawa, I., Stepien, R., Waddie, A.J., Skrabalak, G., Taghizadeh, M.R., Buczynski, R.: Development of glass microoptics for MidIR with hot embossing technology. Proc. SPIE 8428, 84281P (2012)

Kujawa, I., Kasztelanic, R., Stȩpień, R., Klimczak, M., Cimek, J., Waddie, A.J., Taghizadeh, M.R., Buczyński, R.: Optimization of hot embossing method for development of soft glass microcomponents for infrared optics. Opt. Laser Technol. 55, 11-17 (2013)

Lorenc, D., Aranyosiova, M., Buczynski, R., Stepien, R., Bugar, I., Vincze, A., Velic, D.: Nonlinear refractive index of multicomponent glasses designed for fabrication of photonic crystal fibers. Appl. Phys. B: Lasers Opt. 93, 531-538 (2008)

Pan, C.T., Wu, T.T., Chen, M.F., Chang, Y.C., Lee, C.J., Huang, J.C.: Hot embossing of micro-lens array on bulk metallic glass. Sens. Actuators A 141, 422-431 (2008) 
Schubert, A., Edelmann, J., Burkhardt, T.: Micro structuring of borosilicate glass by high-temperature microforming. Microsyst. Technol. 12, 790-795 (2006)

Stepien, R., Buczynski, R., Pysz, D., Kujawa, I., Mirkowska, M., Diduszko, R.: Development of thermally stable tellurite glasses designed for fabrication of microstructured optical fibers. J. Non-Cryst. Solids 357(3), 873-883 (2011)

Takahashi, M., Sugimoto, K., Maeda, R.: Nanoimprint of glass materials with glassy carbon molds fabricated by focused-ion-beam etching. Jpn. J. Appl. Phys. 44, 5600-5605 (2005)

Takahashi, M., Murakoshi, Y., Maeda, R., Hasegawa, K.: Large area micro hot embossing of Pyrex glass with GC mould machined by dicing. Microsyst. Technol. 13, 379-384 (2007)

Waynant, R.W., Ilev, I.K., Gannot, I.: Mid-infrared laser applications in medicine and biology. Philos. Trans. R. Soc. A 359, 635-644 (2001)

Worgull, M.: Hot Embossing, Theory and Technology of Microreplication (Micro and Nano Technologies). William Andrew, Norwich (2009)

Yasui, M., Takahashi, M., Kaneko, S., Tsuchida, T., Hira-bayashi, Y., Sugimoto, K., Uegaki, J.-I., Maeda, R., Uegaki, J-i, Maeda, R.: Micro press molding of borosilicate glass using plated Ni-W molds. Jpn. J. Appl. Phys. 46, 6378-6381 (2007) 